\title{
A CIDADE DE CURITIBA E SEUS ESPAÇOS CENTRAIS DE LAZER
}

\author{
Aline Tschoke \\ Universidade Federal do Paraná, Curitiba, Paraná, Brasil \\ Simone Rechia \\ Universidade Federal do Paraná, Curitiba, Paraná, Brasil \\ Flávia Gonzaga Lopes Vieira \\ Universidade Federal do Paraná, Curitiba, Paraná, Brasil
}

\begin{abstract}
Resumo
Este trabalho tematiza a categoria "espaço" e suas possíveis relações com as práticas sociais e culturais, a partir da observação das diferentes formas de apropriação dos espaços de lazer da cidade de Curitiba- PR. Para tanto, foi realizada uma pesquisa exploratória, objetivando demonstrar que por meio da análise das formas de apropriação desses ambientes é possível perceber que além das dimensões que lhe dão a forma estrutural, o espaço é também palco para a vida cotidiana, os quais ao mesmo tempo em que a constituem são constituídos por ela.
\end{abstract}

Palavras-chave: Atividades de Lazer. Governo Local. Pessoas.

\section{Apresentação}

$\mathrm{E}$ ste trabalho tematiza a categoria "espaço" e suas possíveis relações com as práticas sociais e culturas, a partir da observação das diferentes formas de apropriação dos espaços de lazer da cidade de Curitiba-PR. Para tanto, foi realizada uma pesquisa exploratória e, posteriormente, uma análise detalhada de pesquisas realizadas nessa perspectiva. Ressalta-se que a pesquisa exploratória possibilita ao pesquisador desenvolver a familiaridade com o problema a partir de um levantamento bibliográfico, considerando os mais variados aspectos relativos ao fato estudado, incluindo a análise de exemplos.

A categoria "espaço", segundo Elias (1994), no início das produções científicas, era concebida apenas pela forma concreta significada pela largura, profundidade e comprimento. Entretanto, os estudos avançaram e trouxeram uma ampliação do conceito ao conectá-lo à categoria "tempo". Para o autor, "a localização plena de um facto no espaço não é possível a menos que ela seja acompanhada da sua localização no tempo" (ELIAS, 1994, p. 3). Nessa perspectiva o espaço 
não é a única dimensão dos acontecimentos, estes devem ser situados também num tempo para que tenham sentido, portanto

Neste sentido em sociedades tão complexas como a que vivemos, não é possível dissociar alguns aspectos co-relacionados entre tempo e espaço, pois tais dimensões podem nos auxiliar a compreender as dinâmicas sociais das grandes cidades as quais são engendradas pelo capital.

Pintaudi (2011, p. 167) "afirma que "o espaço que se constrói, no momento atual, poderia ser interpretado com tênue, opaco, expressões que apontam a importância de compreendê-lo no movimento de urbanização que se transforma constantemente". Para a referida autora o espaço, antes produzido com obra, agora é produto, e nesta condição, é repetido infinitas vezes, controlado, indicando um consumo induzido

Dessa maneira, Luchiari (1996, p. 213), defende a "importância dos estudos sobre tais temáticas para compreensão da articulação e organização da sociedade". Para ela, a partir da compreensão de como o espaço é constituído, suas formas de apropriação, suas transformações, os sentidos e significados a ele atribuídos, é possível entender as relações sociais. Nessa mesma perspectiva, espaço e tempo podem ser inseridos na constituição de uma teoria social crítica:

O espaço e o tempo deixam de ser considerados como mera representação ideológica das sociedades e passam a ser assimilados como a materialidade latente, o substrato da vida social que também é passível de uma leitura para investigar o comportamento e a estratificação sociais (LUCHIARI, 1996, p. 218).

Nesse sentido, observamos que as características de altura, largura e profundidade apontadas por Elias (1994) dão forma física ao espaço, mas é a apropriação por parte dos sujeitos que lhe dá sentido e significado. Assim, a partir da relação entre forma, conteúdo e tempo o espaço ganha vida e deixa de ser apenas uma representação tridimensional.

Carlos (2011) ressalta que as novas teorias, no âmbito da constituição do pensamento geográfico brasileiro, também permitem pensar a passagem do conceito de "organização do espaço" àquele de "produção do espaço" e, nessa perspectiva, apontar os fundamentos sociais da produção do espaço. Para ela, esse movimento abre a 
possibilidade de se refletir sobre as relações sociais em sua dimensão espacial, momento em que a espacialidade pode ser tratada como imanente à existência constitutiva da sociedade.

Tais enfoques apontam para a idéia de que a sociedade, ao se produzir, o faz em um espaço determinado, como condição de sua existência e que por meio dessa ação, ela também produz um espaço que lhe é próprio.

Para Bourdieu (2002, p. 38) o espaço físico em si mesmo "não passa do suporte vazio das propriedades sociais dos agentes e instituições que, estando distribuídos por esta superfície, transformam-na em um espaço social, socialmente hierarquizado". A partir do momento em que se transforma em espaço social este passa a nos revelar as regras, as tensões e os signos dos agentes que se apropriam dele.

Essa apropriação está relacionada com o espaço que para Tuan (1983) transforma-se em lugar quando é preenchido por experiências e vivências relacionadas tanto aos sentimentos de dependência quanto de liberdade. Nesse sentido o autor entende que existe uma relação dialética entre essas duas dimensões.

Rechia (2006) salienta que a apropriação de um espaço ou delimitação espacial está ligada ao poder simbólico deste com o lugar, ou seja, com os laços afetivos que as pessoas estabelecem entre si em determinado ambiente. Um exemplo disso, citado pela autora seria a representação de uma quadra esportiva em determinado parque público, que por meio de uma planta, só seria a representação gráfica de uma estrutura físico-espacial - por mais que, evidentemente, essa estrutura reflita e sirva como chave para interpretar determinadas relações sociais, são os processos e práticas ali concretizas, do jogo em si ao confronte entre grupos organizados de usuários, que fornecem sentidos e significados aos processos e práticas sócio-espaciais.

Ao investigar os espaços ${ }^{1}$ encontramos manifestados neles as posições e as oposições constitutivas dos diferentes campos da sociedade. Deste modo os estudos sociológicos são enriquecidos quando contemplarem a categoria espaço, pois este não é somente o pano de fundo onde as relações acontecem, mas constitui e é constituído pela dinâmica social.

1-Pesquisas realizadas pelo GEPLEC- Grupo de Estudos e Pesquisas em Espaços, Lazer e Cidade, localizado no Departamento de Educação Física da Universidade Federal do Paraná coordenado pela Profa. Dra. Simone Rechia.

Pensar a Prática, Goiânia, v. 16, n. 1, p. 1-319, jan./mar. 2013 
Em se tratando de espaços e relações sociais, Forneiro citado por Horn (2004, p. 35) aponta que o termo espaço pode ser relacionado também com o ambiente, sendo assim:

O termo "espaço" se refere aos locais onde as atividades são realizadas, caracterizados por objetos, móveis, materiais didáticos, decoração. O termo "ambiente" diz respeito ao conjunto desse espaço físico e as relações que nele se estabelecem, as quais envolvem os afetos e as relações interpessoais do processo, os adultos e as crianças; ou seja, em relação ao espaço, temos as coisas postas em termos mais objetivos; em relação ao ambiente, as mais subjetivas.

Nessa perspectiva o estudo de um ambiente seria a soma de diferentes espaços e das relações neles e entre eles estabelecidas. A singularidade, que caracteriza cada espaço reside no fato dele ser "[...] algo socialmente construído, refletindo normas sociais e representações culturais que não o tornam neutro e, como conseqüência, retrata hábitos e rituais que contam experiências vividas [...]" (HORN, 2004, p. 37), ou seja, são reflexos e espelhos dos acontecimentos, dos fenômenos, das ações e relações desenvolvidas pelos indivíduos que os planejam, constroem, e principalmente pelos que se apropriam.

$\mathrm{O}$ referido autor salienta ainda que o contexto cultural retrata no espaço "[...] seus símbolos e signos, os quais não são somente criados ou descobertos pelos sujeitos, mas por eles também apropriados" (HORN, 2004, p. 37). Nessa direção, Rechia (2006) discorre que mesmo o espaço sendo planejado para ser apropriado de determinada maneira os sujeitos podem a qualquer instante (re)significá-los. Ou seja, mesmo que os sentidos e significados planejados para este espaço tenham um fim específico, cabe aos indivíduos, pelas diferentes formas de apropriação, aceitar ou alterar esse plano. Portanto, essa relação planejamento- espaço- indivíduo é dinâmica.

Nessa perspectiva Milton Santos (1997, p. 25) salienta que o "lugar constitui a dimensão da existência que se manifesta através de um cotidiano compartilhado entre as mais diversas pessoas, firmas, instituições-cooperação que em conflito são a base da vida em comum", essa reflexão reafirma que as relações sociais e a apropriação do espaço podem desvendar os sentidos e significados nas ações cotidianas. 
Em síntese, para Rechia e França (2006, p. 63), o "espaço e lugar são componentes básicos do mundo vivido. Assim, o que começa como espaço indiferenciado transforma-se em lugar à medida que o conhecemos melhor e o dotamos de valor". Nessa perspectiva a análise do espaço assume uma importância no contexto da modernidade, visto que o espaço "transforma-se no modo privilegiado de pensar e agir o fim do século. Assim sendo, é de se pensar que as representações sociais do espaço adquiriram cada vez mais importância e centralidade analíticas." (SANTOS, 2006, p. 63).

Fazendo correspondência direta entre a organização social e a organização do espaço, Bourdieu (2002) aponta que os ocupantes das posições dominantes nos diferentes campos - por exemplo, a classe econômica mais privilegiada - tendem a ocupar as posições dominantes do espaço social. Deste modo percebemos um jogo de homologias, onde as distribuições espaciais dos diferentes campos tendem a sobrepor-se. Um exemplo muito claro desse jogo homólogo é a distribuição espacial das cidades onde o capital econômico está diretamente relacionado à distribuição das moradias pelos bairros. Além disso, podemos perceber que o capital econômico também define o acesso a determinados espaços onde as barreiras podem ser tanto objetivas quanto simbólicas. Desta maneira o autor afirma que a distribuição do espaço social é definida pela "relação entre bens distribuídos no espaço e agentes definidos por capacidades desiguais de apropriação de tais bens" (BOURDIEU, 2002, p. 38).

\section{Um passeio pelos espaços centrais de Curitiba}

Passeando pelos espaços centrais de lazer de Curitiba podemos observar a distribuição das classes sociais em ambientes diferenciados. No caso dos teatros e shoppings, a distribuição no espaço se aproxima de forma mais visível da distribuição no "campo". Os shoppings reagrupam todas as instituições que ocupam a posição dominante em seus respectivos campos. Em um passeio por estes espaços em Curitiba podemos encontrar várias lojas de grifes internacionais que não podem ser encontradas nas ruas da cidade, além disso, percebemos que as maiores empresas sempre estão presentes nestes estabelecimentos (como Mc Donalds, C\&A, etc.), tanto que quando vamos a um shopping temos a certeza de que poderemos encontrá-las. Acrescentamos que estes locais apresentam uma unidade no modo de fun- 
cionar, nos estabelecimentos constituintes e no público alvo. Como afirma Bourdieu (2002, p. 33):

As instituições da produção e difusão de bens culturais tendem a organizar-se em sistemas que, entre si, são homólogos de forma estrutural e funcional, além de manterem uma relação de homologia estrutural com o campo das frações da classe dominante (na qual é recrutada a maior parte de sua clientela).

Entretanto, esses espaços podem gerar conflitos sociais, pois espaços como shoppings e teatros são frequentados por certas pessoas que se distinguem socialmente por esta prática, portanto espaços como estes podem ser segregadores. Esse fenômeno pôde ser claramente observado na polêmica proibição de um grupo de jovens integrantes do movimento hip-hop de entrar no mais novo shopping da cidade de Curitiba, segundo o Jornal Gazeta do Povo (2008, P.7), simplesmente porque não atenderam aos padrões sociais impostos para aquele lugar.

Continuando o passeio, agora pelos teatros da cidade de Curitiba, podemos observar a diferença entre o que Bourdieu denomina "teatro burguês" e "teatro de vanguarda". Conseguimos perceber diferenças nas características sociais do público, dos autores representados, das próprias companhias de teatro.

Se atentarmos para o Teatro Guaíra ${ }^{2}$ e o Teatro Positivo $^{3}$, fica claro que estes se enquadram perfeitamente nas características do teatro burguês, pois são instituições que:

Preocupadas com a rentabilidade econômica são impingidas a utilizar estratégias culturais de extrema prudência propondo espetáculos - já representados ou concebidos segundo receitas seguras e confirmadas - a um público adulto burguês disposto a pagar preços elevados para assistirem a um espetáculo de simples diversão (BOURDIEU, 2002, p. 34).

2-Localizado na Rua XV de Novembro, 971, Curitiba-PR, no centro da cidade. Tem capacidade para 2.149, e integra o Centro Cultural Teatro Guaíra, os ingressos custam em média 150 reais na platéia.

3-Inaugurado em marco de 2008, está localizado na Rua Prof. Pedro Viriato Parigot de Souza, 5300. Campo Comprido - Curitiba. Tem capacidade para 2400, e faz parte do Campus da Universidade Positivo, os ingressos custam em média 150 reais na platéia.

Pensar a Prática, Goiânia, v. 16, n. 1, p. 1-319, jan./mar. 2013 
As peças apresentadas nestes teatros geralmente são aquelas de grandes diretores já reconhecidos, com atores 'globais', e variam entre peças famosas rearranjadas e comédias exibidas a preços altos, sempre para o mesmo público.

Quanto aos outros teatros da cidade (Teatro Barracão em Cena, Teatro Laila Schineider, Teatro Novelas Curitibanas, Teatro José Maria Santos, Teatro João Luis Fiani, Espaço Cultural Pé no Palco, Teatro Universitário de Curitiba, entre outros), os quais são de menor porte e menos conhecidos, caracterizam-se por instituições que, do ponto de vista econômico e cultural, correm riscos, "e que propõe, a preços relativamente reduzidos, espetáculos em ruptura com as convenções e destinados a um público jovem e intelectual" (BOURDIEU, 2002 , p. 34). Nestes estabelecimentos os espetáculos podem ser mais ousados e inovadores, pois seu objetivo principal não é o ganho econômico e sim a produção e a divulgação da arte. Portanto, essas duas dimensões, teatro burguês e teatro de vanguarda, coexistem no meio urbano.

\section{Espaços centrais e as relações com o exercício político}

O que se observa é que o espaço público permite que haja movimentos de resistências capazes de transformar os espaços em lugares singulares. Em Curitiba percebemos alguns desses lugares, como, por exemplo, o Largo da Ordem (parte histórica da cidade, ou seja, o seu marco zero) e a Rua XV de Novembro, o chamado "calçadão" (primeira rua fechada só para pedestres).

Localizada entre a Praça Osório e a Rua XV de Novembro, encontramos a 'Boca Maldita'4, definida como local onde pode-se falar e ouvir de tudo sem censura. De acordo com Vieira (2010, p. 85),

Esse espaço surgiu espontaneamente do encontro entre as pessoas que se reuniam para discutir, principalmente, sobre a polí-

4-Segundo Curitiba (2008), A Boca Maldita é considerada uma "Tribuna livre criada em 1957 e institucionalizada em 13 de dezembro de 1966. Um dos fundadores, Anfrísio Siqueira, é seu eterno presidente. Poderosa e machista, a Boca é famosa desde que se atribuiu a ela a responsabilidade pela cassação, nos anos 70, do governador do Estado Haroldo Leon Peres. Seu lema é 'nada vejo, nada ouço, nada falo'. Durante a ditadura militar, funcionou como tribuna livre. Fica no calçadão da Avenida Luiz Xavier, em frente aos cafés".

Pensar a Prática, Goiânia, v. 16, n. 1, p. 1-319, jan./mar. 2013 
tica nacional", e segue dizendo que a "boca" tornou-se um espaço político tão importante que grande parte das manifestações que ocorrem na cidade têm como palco a Boca Maldita.

Essa possibilidade gerada pelo encontro das pessoas em um espaço aberto, público e institucionalizado, tornou-se um espaço político tão importante para a cidade que podemos citar dois fatos marcantes. O primeiro foi a cassação do governador do estado na década de 1970, e principalmente, o lançamento da campanha "Diretas Já", ocorrida no ano de 1984, que buscava, além do fim da ditadura militar, eleger um Presidente da República de maneira direta. Essa manifestação reuniu cerca de 50 mil pessoas na Boca Maldita e deu início a manifestações por todo o Brasil.

$\mathrm{Na}$ mesma perspectiva de possibilitar o encontro entre os sujeitos, o segundo fato marcante para a cidade foi a restauração do Largo da Ordem, possibilitando um acesso livre aos pedestres - também é fechado para carros -, que se consolidou como espaço de lazer noturno, por possuir um grande número de restaurantes e bares. Embora não possua um local político institucionalizado, o Largo também apresenta essa possibilidade por meio das bancas de jornal. FERNANDES (2010), em uma reportagem do jornal Gazeta do Povo intitulada "E Deus inventou a banquinha" demonstra a relação entre esses usos e a importância das bancas de jornal instaladas nas praças da cidade. Essa reportagem mostra que o comércio nos espaços públicos pode ultrapassar os limites de compra e vendas de produtos, como vemos nas palavras do autor "[...] as lojinhas apertadas em cima da calçada são espaços democráticos para troca de idéias e criação de vínculos de vizinhança". Dorival Carneiro, dono de banca e entrevistado para a reportagem confirma dizendo que: "uma banca é uma referência. Nos perguntam onde fica uma rua, mas também o que pensamos sobre as eleições. Somos bons ouvintes, informantes, formadores de opinião."

As bancas de jornal em Curitiba se tornaram ponto de referência para a cidade e lugar de sociabilidade entre os frequentadores de tais espaços. Essa possibilidade de convivência entre as pessoas fez com que dois jornaleiros tomassem atitudes que propiciam esse espaço de convivência: $\mathrm{O}$ exemplo mais citado é o da minipraça criada pelo jornalista e jornaleiro Gregório de Bem, na ciclovia do Hugo Lange. Mais do que um ponto de venda, a banquinha é ponto de convivência no bairro, muitos vizinhos se reúnem em seu entorno para conversar e 
discutir assuntos referentes às problemáticas do lugar. Já Daniel Barbosa da Silva, 53 anos, criou uma confraria de leitores que se reúnem na banca - de frente para o Clube Atlético - no domingo de manhã, tornando o lugar um ponto de encontro para discutir obras literárias.

Esses fatos corroboram com a idéia de Jacobs (2000) que o comércio é necessário para a diversidade da cidade, mas que ao conectálo com atrativos culturais tais espaços passam a ter vida. Vemos que essas bancas de jornal citadas parecem possibilitar tal vida e diversidade.

Ainda em outros espaços da cidade, destinados essencialmente à vivência do lazer, como é o caso dos parques, é possível observar certos movimentos de resistência porque oferecem um tempo e espaço de lazer que, muitas vezes, se diferencia da lógica da indústria cultural, como vemos nos shoppings e teatros. A forma com que as pessoas se apropriam desses espaços indica tal afirmação. França (2007) monstra, em seu estudo sobre o parque São Lourenço, o sentimento de pertencimento dos sujeitos frequentadores em relação ao parque. Tal sentimento proporciona um cuidado especial com o lugar observado através das ações da Associação do Parque São Lourenço.

Já no caso de uma pesquisa realizada na Praça Afonso Botelho, Cagnato (2007) encontrou relações significativas da aproximação dos usuários com as praças, a partir das experiências no âmbito do esporte e do lazer, propiciando o surgimento de grupos organizados. A mesma autora aponta ainda que "[...] há nesta praça um encontro diário de pessoas e grupos que se formam em função de práticas específicas, em função de laços afetivos com o lugar." (CAGNATO, 2007, p. 96).

Tendo em vista o que foi até agora mencionado, podemos afirmar que o espaço é muito mais do que apenas dimensões gráficas representadas por números, é nele que as diferenças econômicas, sociais e culturais se materializam e, ao mesmo tempo, é onde essas diferenças são resolvidas.

\section{Algumas reflexões}

Articulando os conceitos de espaço apresentados e uma possível interpretação dos laços sociais que se formam nesses lugares, podemos afirmar que o espaço faz parte da dinâmica das relações sociais. Desta maneira, as pesquisas não podem deixar de investigar a categoria espacial e sua relevância, pois além de conter um aspecto tridi- 
mensional, quando apropriado, os espaços transformam-se em lugares dotados de sentidos e significados que os tornam meios capazes de auxiliar na compreensão das representações sociais. Somado a isso, a distribuição e dinâmica do espaço podem revelar as diferenças entre as classes sociais, assim como a constituição de grupos singulares no meio urbano.

Nesse contexto a relação entre essas experiências no âmbito do lazer e a Educação Física está no corpo, pois do corpo nascem e se propagam as significações que fundamentam a existência individual e coletiva; ele é o eixo da relação com o mundo, o lugar e o tempo nos quais a existência toma forma através da fisionomia singular de um ator. Para Le Breton (2010, p. 8)

[...] existir significa em primeiro lugar mover-se em determinado espaço e tempo [...] pela corporeidade, o homem faz do mundo a extensão de sua experiência transformando-o em tramas familiares e coerentes, disponíveis à ação e permeáveis. Emissor ou receptor, o corpo produz sentidos continuamente e assim insere o homem, de forma ativa, no interior de dado espaço social e cultural.

Sendo assim, fica claro que tratar do espaço apenas como dimensão física é reduzir o seu potencial de análise, pois é no espaço, no tempo - e também no corpo - que as relações sociais acontecem e se concretizam. Ainda para o referido autor

[...] a compreensão da corporeidade humana como fenômeno social, e cultural, motivo simbólico, objeto de representações e imaginários sugere que as ações que tecem a vida cotidiana das mais fúteis ou menos concretas até aquelas que ocorrem na cena pública - envolvem mediação da corporeidade". (LE BRETON, 2010, p.10)

Dessa forma, fica evidente que estudar a categoria "espaço" na área de Educação Física nos permite compreender os fenômenos sociais da atualidade - também de épocas passadas -, já que o espaço não se constitui como uma categoria inerte na vida das cidades e dos cidadãos que nelas vivem. Os espaços possuem uma certa dinâmica que 
lhes é única: a possibilidade da materialização dos laços sociais por meio do corpo.

\title{
The city of Curitiba and their areas of central leisure
}

\begin{abstract}
This paper studies the category "space" and its relationship with certain social actors, from the observation of different forms of ownership of some leisure facilities in the city of Curitiba-PR. To this end, we conducted an exploratory study aiming to demonstrate that by analyzing the forms of appropriation of these environments you can see that beyond the dimensions which give the structural form, space is also the venue for daily life, which at the same time that are made up for it.
\end{abstract}

Keywords: Leisure Activities. Local Government. Persons.

\section{La ciudad de Curitiba y sus áreas de ocio central}

\section{Resumen}

Este trabajo estudia la categoría de "espacio" y su relación con ciertos actores sociales, de la observación de las diferentes formas de propiedad de algunas instalaciones de ocio en la ciudad de Curitiba-PR. Para ello, llevamos a cabo un estudio exploratorio con el objetivo de demostrar que mediante el análisis de las formas de apropiación de estos ambientes se puede ver que más allá de las dimensiones que dan la forma estructural, el espacio es también el lugar para la vida diaria, que al mismo tiempo momento en que fueron compuestos por él.

Palabras clave: Actividades Recreativas. Gobierno Local. Personas.

\section{Referências}

BOURDIEU, P. A Produção da Crença: contribuição para uma economia dos bens simbólicos. São Paulo: Zouk, 2002.

CARLOS. A.F. A. Da "organização" à "produção" do espaço no movimentodo pensamento geográfico. In: ALESSANDRI, A. C.; SOUZA, M. L.; SPOSITO M. E. B. (Orgs.). A produção do espaço urbano: agentes, processos, escalas e desafios. São Paulo: Contexto, 2011. p.53-75

CAGNATO, E. V. Praça Afonso Botelho: o foco das observações no âmbito do esporte e do lazer. 2007. 105p. Dissertação (Mestrado) Universidade Federal do Paraná, Curitiba, 2007.

CURITIBA. Site da Prefeitura Municipal de Curitiba. Roteiros da cidade. Boca Maldita. Disponível em: <http://www.curiti- 
ba.pr.gov.br/pmc/a_cidade/Roteiros/LinhaPinhao/47.html>. Acesso em 11 de fevereiro de 2009.

ELIAS, N. Teoria Simbólica. Oeiras: Celta Editora, 1994.

FERNANDES, J. C. E Deus inventou a banquinha. Gazeta do povo, Curitiba, out. 2010. Seção Vida e Cidadania. Disponível em $<$ http://www.gazetadopovo.com.br/vidaecidadania/conteudo.phtml?id=1055783\&tit=E-Deus-inventou-a-banquinha $>$. Acesso em 25 de maio de 2013.

FRANÇA, R. Diálogos entre oferta e demanda: uma análise da relação entre o poder público e os grupos de ativismos sociais referentes aos parques da cidade de Curitiba. 2007. 134p. Dissertação (Mestrado) - Departamento de Educação Física, Universidade Federal do Paraná, Curitiba, 2007.

GAZETA DO POVO. Curitiba, 27 maio 2008, p. 7.

HORN, M. da G. S. Sabores, cores, sons, aromas: a organização dos espaços na Educação Infantil. Porto Alegre: Artmed, 2004.

JACOBS, J. Morte e vida de grandes cidades. São Paulo: Martins Fontes, 2000.

LE BETRON, D. A sociologia do corpo. Tradução de Sonia M.S. Fuhrmann. 4. ed. Petrópolis, RJ: Vozes, 2010.

LEFEBVRE, H. O Direito à Cidade. Tradução de Rubens Eduardo Frias. São Paulo: Centauro, 2001.

LUCHIARI, M. T. A categoria espaço na teoria social. Revista Temáticas, Campinas, ano 4, n. 7, p. 191-238, jan./jun. 1996.

PINTAUDI, S. M. Mercados públicos: vestígios de um lugar. In: ALESSANDRI, A. C.; SOUZA, M. L.; SPOSITO M. E. B. (Orgs.). A produção do espaço urbano: agentes, processos, escalas e desafios. São Paulo: Contexto, 2011. p.167-177.

RECHIA, S. O jogo do espaço e o espaço do jogo em escolas da cidade de Curitiba. Revista brasileira de Ciências do esporte, Campinas, v. 22, n. 2, p. 91-104, jan., 2006. 
RECHIA, S.; FRANÇA, R. O Estado do Paraná e seus espaços e equipamentos de lazer e esporte: apropriação, desapropriação ou reapropriação. In: MEZZADRI, F. M.; CAVICHIOLLI, F. R.; SOUZA, D. L. Lazer e esporte: subsídios para o desenvolvimento e a gestão de políticas públicas. Jundiaí: Fontoura, 2006. p. 61-74.

SANTOS, M. Metamorfose do espaço habitado. 5. ed. São Paulo: Hucitec, 1997.

. A natureza do espaço: técnicas e tempo, razão e emoção. 4. ed. 2. reimpr. São Paulo: Edusp, 2006.

TUAN, Y. Espaço e lugar: a perspectiva da experiência. Tradução de Lívia de Oliveira. São Paulo: Difel, 1983.

VIEIRA, F. G. Espaços públicos de lazer no centro de Curitiba: a transformação da cidade urbana para cidade humana. 2010. 104p. Dissertação (Mestrado)-Departamento de Educação Física, Universidade Federal do Paraná, Curitiba, 2010.

Recebido em: 26/03/2011

Revisado em: 17/06/2011

Aprovado em: 15/12/2011

Endereço para correspondência

simone@ufpr.br

Simone Rechia

Universidade Federal do Paraná, Setor de Ciências Biológicas

Departamento de Educação Física.

Centro Politécnico

Jardim das Américas

81530900 - Curitiba, PR - Brasil - Caixa-postal: 19031 